\title{
Whole genome sequencing analysis of multiple Salmonella serovars provides insights into phylogenetic relatedness, antimicrobial resistance, and virulence markers across humans, food animals and agriculture environmental sources
}

\author{
Suchawan Pornsukarom ${ }^{1}$, Arnoud H M van Vliet ${ }^{2}$ (D) and Siddhartha Thakur ${ }^{3,4^{*}}$ (D)
}

\begin{abstract}
Background: Salmonella enterica is a significant foodborne pathogen, which can be transmitted via several distinct routes, and reports on acquisition of antimicrobial resistance (AMR) are increasing. To better understand the association between human Salmonella clinical isolates and the potential environmental/animal reservoirs, whole genome sequencing (WGS) was used to investigate the epidemiology and AMR patterns within Salmonella isolates from two adjacent US states.

Results: WGS data of 200 S. enterica isolates recovered from human $(n=44)$, swine $(n=32)$, poultry $(n=22)$, and farm environment $(n=102)$ were used for in silico prediction of serovar, distribution of virulence genes, and phylogenetically clustered using core genome single nucleotide polymorphism (SNP) and feature frequency profiling (FFP). Furthermore, AMR was studied both by genotypic prediction using five curated AMR databases, and compared to phenotypic AMR using broth microdilution. Core genome SNP-based and FFP-based phylogenetic trees showed consistent clustering of isolates into the respective serovars, and suggested clustering of isolates based on the source of isolation. The overall correlation of phenotypic and genotypic AMR was $87.61 \%$ and $97.13 \%$ for sensitivity and specificity, respectively. AMR and virulence genes clustered with the Salmonella serovars, while there were also associations between the presence of virulence genes in both animal/environmental isolates and human clinical samples.

Conclusions: WGS is a helpful tool for Salmonella phylogenetic analysis, AMR and virulence gene predictions. The clinical isolates clustered closely with animal and environmental isolates, suggesting that animals and environment are potential sources for dissemination of AMR and virulence genes between Salmonella serovars.
\end{abstract}

Keywords: Salmonella, WGS, Core genome, SNP, FFP, Antimicrobial resistance, Virulence gene, Plasmid, Human, Swine, Poultry, Environment

\footnotetext{
* Correspondence: sthakur@ncsu.edu

${ }^{3}$ Department of Population Health and Pathobiology, College of Veterinary

Medicine, North Carolina State University, Raleigh, NC, USA

${ }^{4}$ Comparative Medicine Institute, North Carolina State University, Raleigh, NC,

USA

Full list of author information is available at the end of the article
}

(c) The Author(s). 2018 Open Access This article is distributed under the terms of the Creative Commons Attribution 4.0 International License (http://creativecommons.org/licenses/by/4.0/), which permits unrestricted use, distribution, and reproduction in any medium, provided you give appropriate credit to the original author(s) and the source, provide a link to the Creative Commons license, and indicate if changes were made. The Creative Commons Public Domain Dedication waiver (http://creativecommons.org/publicdomain/zero/1.0/) applies to the data made available in this article, unless otherwise stated. 


\section{Background}

Infection with antimicrobial resistant Salmonella in humans and animals is a global threat that has caught the public attention worldwide [1-3]. Human foodborne salmonellosis causes an estimated 100,000 domestic cases and 40 deaths annually in the United States [1]. The U.S. Department of Health and Human Services reported an increase in Salmonella infections from 13.6 to 16.4 cases per 100,000 population, which represented a 17.1\% increase from 1997 to 2011 [4]. In the European Union, Salmonella-infected gastroenteritis was the second most frequently reported foodborne illness with 91,408 clinical cases reported by thirty EU/EEA countries, and a confirmed case rate of 25.4 cases per 100,000 population in 2014 compared to 21.4 cases per 100,000 population in 2013 , which represented a $19 \%$ increase in the notification rate [3].

Inappropriate use of antimicrobials in livestock production and the association to resistant Salmonella infection in humans are a growing concern to public health agencies, and have led to the rise of new multidrug resistant (MDR) bacteria and transferable genetic loci, such as colistin resistance mediated by the MCR-1 gene $[5,6]$. Given the ever-growing requirement to maintain the efficacy of antimicrobials as well as decrease the emergence of antimicrobial resistance in human infections, the antimicrobial use in veterinary and agricultural practices is being extensively re-evaluated [7-9]. Humans and animals are linked to each other through the environmental reservoirs which have long been implicated as a source of Salmonella and antimicrobial resistance found in human and animals [8-10]. The selection pressure on Salmonella is created by antimicrobial use in human health and food animal production leading to development and potential spread of antimicrobial resistance [8-11]. Our previous studies reported the persistence and dissemination of multiple resistant Salmonella serovars along with their determinants in the environment of commercial swine operation due to the manure application on land $[12,13]$.

Multiple Salmonella serovars, including Agona, Anatum, Derby, Heidelberg, Infantis, Kentucky, Muenchen, Newport, Schwarzengrund, and Typhimurium are commonly detected in food animals, food products, and agricultural environments, and are associated with resistant Salmonella infections in humans [14-17]. The Centers for Disease Control and Prevention (CDC) reported that the incidence of human Salmonella infections caused by monophasic 4,[5],12:i:-, which is in the top 4 of the most frequently reported Salmonella serovars, continue to rise while the incidence of the other serovars is decreasing [16]. The increase in the incidence of this serovar in human cases is paralleled by a similar increase in swine and environmental detection of this serovar variant $[12,13,18]$. However, there are gaps that still exist in our understanding of the temporal and spatial connection of resistant Salmonella transmission within humans, animals, and the environment sources.

A number of studies have used the classical molecular typing methods such as pulsed-field gel electrophoresis (PFGE), multilocus sequence-based typing (MLST), and multilocus variable-number tandem repeat analysis (MLVA) to assess the relatedness and the subsequent transmission of antimicrobial resistant (AMR) Salmonella in human, animals, and environment [19-21]. However, the limitation of these methods lies in insufficient discriminatory power to separate closely related Salmonella isolates in outbreak investigations and to differentiate between the intra-serovar isolates from different hosts [20-22]. The use of whole genome sequencing (WGS) has had a major impact on the study of the molecular epidemiology of AMR bacterial pathogens associated and transmitted between human, animal and environmental sources. A WGS study in Denmark reported that SNP, pan-genome, k-mer and nucleotide difference trees were superior to the classical typing method and evaluated the association of the isolates to specific outbreaks of $S$. Typhimurium [23]. Additionally, WGS has been used to identify known AMR determinants among strains of Escherichia coli and Salmonella $[24,25]$. The objectives of this study were to use WGS to analyze multiple Salmonella serovars isolated from human, food-animals and environments in the two states of the US and to clarify the epidemiological transmission of AMR Salmonella within these studied populations. In addition, the capability of WGS to predict antimicrobial resistance and virulence genes in antimicrobial resistant Salmonella retrieved from different sources was evaluated.

\section{Results}

\section{Salmonella serotyping based on WGS}

The 200 Salmonella sequences in this study selected from human clinical cases, swine, poultry, and environmental samples were serotyped using the SISTR platform for confirmation [26], and showed a high level of serotype diversity (Table 1$)$. The predominant serovars which originated from multiple sources were Derby $(n=$ $21)$, Kentucky $(n=5)$, Johannesburg $(n=9)$, Mbandaka $(n=12)$, Rissen $(n=14), \quad$ Schwarzengrund $(n=22)$, Senftenberg $(n=12)$, Typhimurium $(n=39)$, and 4,[5],12:i:$(n=8)$.

\section{Comparison of FFP with SNP-based phylogeny of Salmonella isolates}

The 200 Salmonella enterica genomes were assessed for their phylogenetic relationships using core genome SNPs with the ParSNP program [27] and feature frequency profiling with the FFPry program [28]. Isolates clustered 
Table 1 Number of Salmonella isolates $(n=200)$ from human, animal, and environment by serotype sequenced for comparison

\begin{tabular}{|c|c|c|c|c|c|}
\hline \multirow{2}{*}{$\begin{array}{l}\text { Salmonella } \\
\text { serotype (n) }\end{array}$} & \multicolumn{5}{|l|}{ Source of isolate } \\
\hline & Human $(n=44)$ & Swine $(n=32)$ & Poultry $(n=22)$ & Environment $(n=102)$ & Total $(n=200)$ \\
\hline Altona & & & & 11 & 11 \\
\hline Anatum & & & & 1 & 1 \\
\hline Braenderup & & & & 1 & 1 \\
\hline Chester & 1 & & & & 1 \\
\hline Derby & 9 & 7 & & 5 & 21 \\
\hline Enteritidis & 1 & & & & 1 \\
\hline Heidelburg & 1 & & & 1 & 2 \\
\hline Kentucky & & & 4 & 1 & 5 \\
\hline Johannesburg & & 4 & & 5 & 9 \\
\hline Mbandaka & 1 & 3 & 3 & 5 & 12 \\
\hline Muenchen & 9 & & & & 9 \\
\hline Muenster & & & & 16 & 16 \\
\hline Ouakam & & 1 & & & 1 \\
\hline Rissen & & 6 & & 8 & 14 \\
\hline Schwarzengrund & 7 & & 7 & 8 & 22 \\
\hline Senftenberg & & 6 & 3 & 3 & 12 \\
\hline Typhimurium & 15 & 5 & 1 & 18 & 39 \\
\hline 4,[5],12:i:- & & & 4 & 4 & 8 \\
\hline Uganda & & & & 4 & 4 \\
\hline Worthington & & & & 11 & 11 \\
\hline
\end{tabular}

according to serotype with both analysis methods, and the topology of the resulting phylogenetic trees was very similar (Fig. 1). Although the order of specific serovars did differ, the 200 Salmonella genomes clustered into 10 different major groups matching the respective serovars in both parSNP and FFPry trees. The differences in order of the clusters between the FFPry and parSNP trees may be explained by the parSNP tree being based on the core genome only, thus excluding phages, plasmids and regions of horizontal gene transfer. In addition, many major serovar clusters were comprised of the genomes from different sources of origin including human, animal, and the environment. There were several singleton genomes that did not cluster into any major serotype-associated group. Therefore, these differences have a relatively small effect on the general structure of the trees and the clustering observed. ParSNP reported coverage over the genome for each run, and when all 200 Salmonella genomes were included, the average coverage was $77.6 \%$. For the individual serovars, these were $89.4 \%$ (Fig. 2, Typhimurium and 4,[5],12:i:-), 85.3\% (Fig. 3, Derby), 89.0\% (Fig. 4, Schwarzengrund) and $97.9 \%$ (Fig. 5, Rissen).

We focused on these major clusters for serovars Typhimurium, Derby, Schwarzengrund, and Rissen (Figs. $2,3,4,5)$. These clusters were comprised of the genomes from multiple sources. $S$. Typhimurium and $S .4$,[5],12:i:genomes recovered from human, swine, poultry, and environmental sources clustered together (Fig. 2). The genomes from the same origin have a close relationship as indicated by the positioning on the phylogenetic SNP tree. However, a human clinical fecal (HS71549) was closely grouped along with environmental isolates from the commercial swine farms. Another human case genome (HS5826) was placed near the swine samples on the tree. The genomes of serotype 4,[5],12:i:- recovered from both chicken fecal and environment were grouped close to each other, most likely because they originated from the same farm in Tennessee.

The isolates with serotype Derby showed little variation in the core genome, nor was any specific clustering linked with human, swine, and environmental sources (Fig. 3). In contrast, the isolates of $S$. Schwarzengrund (Fig. 4) showed isolation source-specific clustering of human isolates separate from the group of chicken fecal and environmental genomes, with the exception of two isolates from human clinical cases (HS5256 and HS61650). The environmental samples of this serotype were from the litter and the fly traps collected from the chicken farms. The genomes of $S$. Rissen clustered based on the source of isolates (Fig. 5). The swine fecal genomes were grouped together, while the soil and lagoon genomes even collected from the different 


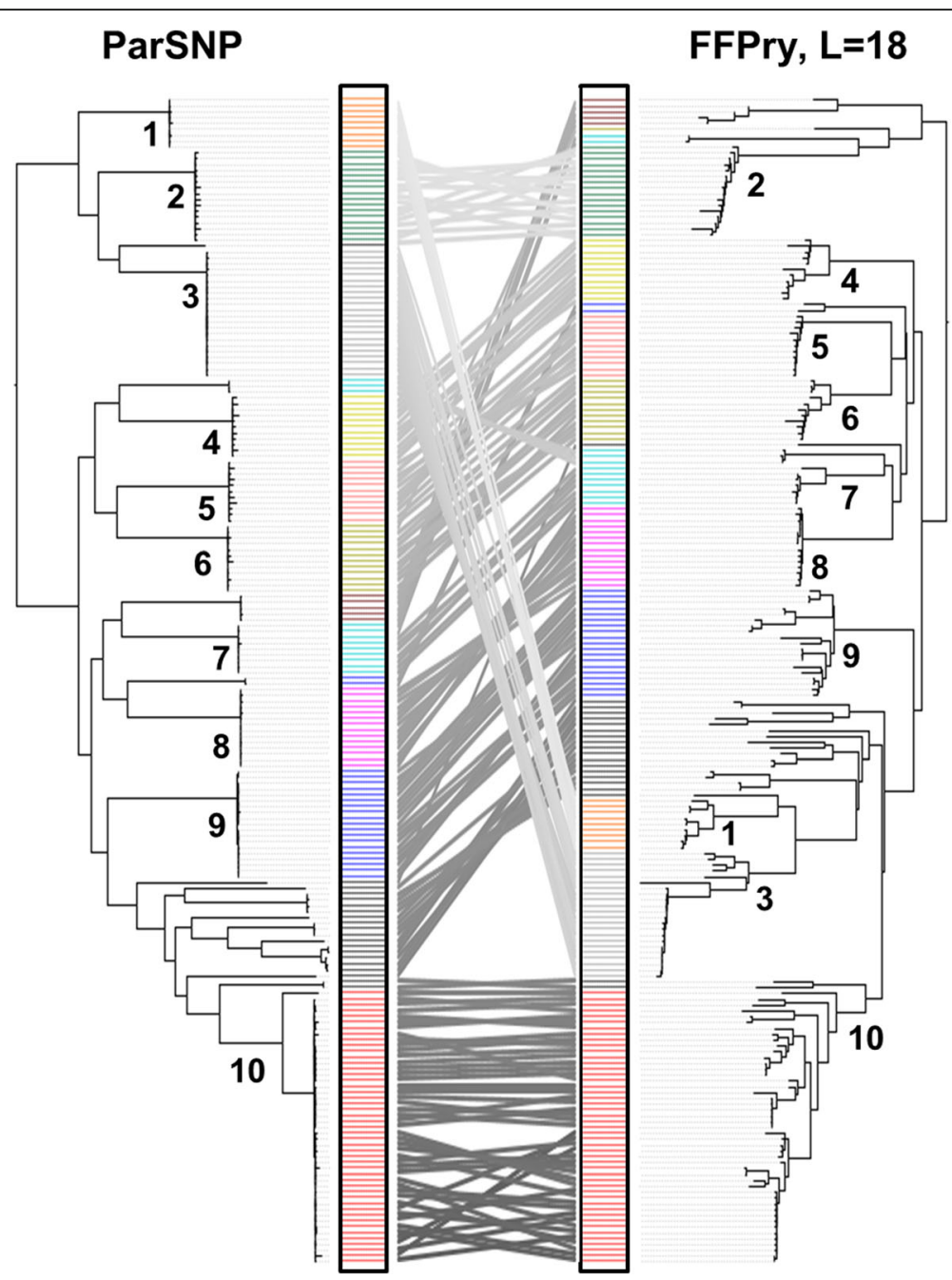

Fig. 1 Comparison of Salmonella enterica phylogenetic trees based on core genome single nucleotide polymorphisms using ParSNP [27] and the alignment-free whole genome comparison with feature frequency profiling of purine-pyrimidine words (FFPry) with a word length (L) of 18 [28], using the 200 Salmonella genomes included here, visualised using the serovars (colored bar) and a tanglegram in the middle to indicate position of individual genomes in both phylogenetic trees. The left panel represents the phylogenetic tree based on core genome SNPs, while the right panel shows the phylogenetic tree obtained FFPry. Note that although the order of serotypes differs, isolates cluster generally according to serotype in both analysis methods, with the overall topology being similar. Clusters containing major serovars are indicated by numbers: 1. Johannesburg; 2. Muenster; 3. Schwarzengrund; 4. Worthington; 5. Altona; 6. Mbandaka; 7. Senftenberg; 8. Rissen; 9. Derby; 10. Typimurium and $4,[5], 12: i:-$

farms and time points still clustered together and separated from swine branch.

\section{Detection of AMR genes, plasmid replicons, and virulence genes using WGS}

The WGS data was used to detect the presence and absence of AMR genes, plasmid replicon, and virulence genes in the 200 Salmonella genomes (Figs. 6 and Additional file 1: Figure S1). Overall, the most common resistance genes detected were sul 1 (32.5\%), tet $\mathrm{R}(28.5 \%)$, and tetA (24\%) (Additional file 2: Table S2). The three most frequent replicons, including ColRNAI, IncFIB, and IncFII were detected in $43 \%, 16 \%$, and $15.5 \%$ of all
Salmonella sequences, respectively (Additional file 2: Table S2). In addition, the 200 Salmonella genomes were also screened for virulence genes. One hundred and seventy-five virulence genes were detected in this study using WGS (Additional file 2: Table S2). All 200 isolates were positive for thirty-nine virulence genes, including $\operatorname{inv} \mathrm{A}, \operatorname{sip} \mathrm{B}, \operatorname{prg} \mathrm{H}, \operatorname{spa}, \operatorname{rrg} \mathrm{A}, \operatorname{iro} \mathrm{N}, \operatorname{sif} \mathrm{A}$, and $\operatorname{sop} \mathrm{B}$ (Additional file 2: Table S2).

\section{AMR correlation based on phenotypic (MIC) and genotypic data (WGS)}

Genome sequence data were correlated with the phenotypic AMR profiles to evaluate the ability of WGS to 


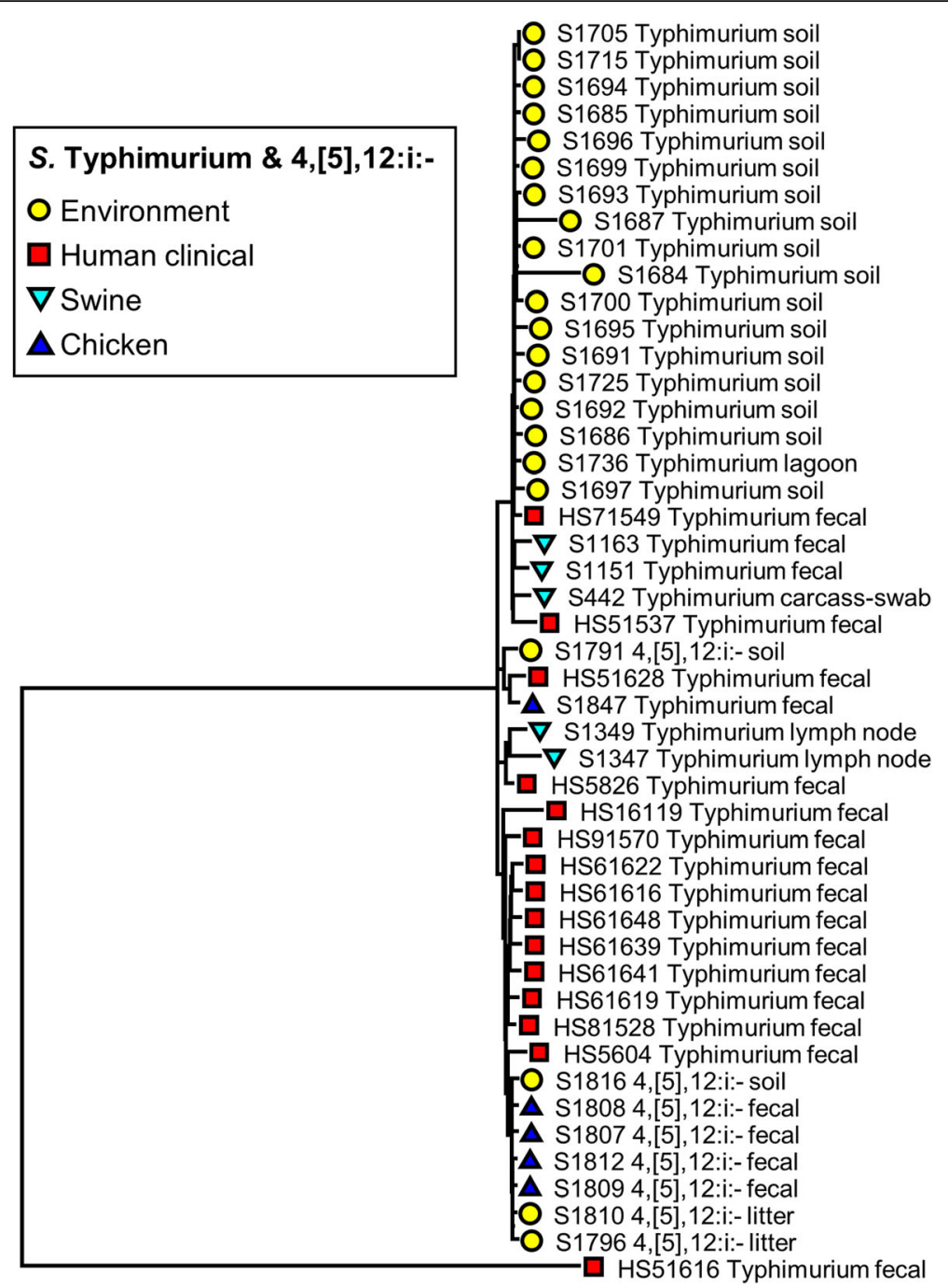

Fig. 2 Phylogenetic tree of S. Typhimurium and S. 4,[5],12:i:- isolates $(n=47)$ recovered from human, swine, chicken, and environmental sources constructed using parSNP analysis. Colored markers indicate the source of each isolate, with more details added to the name of each isolate

predict phenotypic resistance (Figs. 6 and Additional file 1: Figure S1). The most frequent AMR phenotypes were resistance against streptomycin (STR; 57.5\%), tetracycline (TET; 51\%), and sulfisoxazole (FIS; 46\%) (Additional file 2: Table S1). Resistance to azithromycin, ciprofloxacin and nalidixic acid was not detected in this study and, therefore, not included for evaluation. Overall, phenotypic resistance correlated strongly with the presence of corresponding AMR determinants using WGS (Table 2). The overall sensitivity of AMR coding genes present for predicting resistance across all antimicrobials was $87.61 \%$, the specificity was $97.13 \%$, the positive predictive value (PPV) was $88.35 \%$, and the negative predictive value (NPV) was $96.93 \%$ as shown in Table 2. The genotypic prediction of phenotypic resistance to sulfisoxazole (FIS), tetracyclines (TET), and cephems (ceftriaxone, CRO; cefoxitin, FOX; ceftiofur, XNL) had a sensitivity over $90 \%$, while the other sensitivity values for other antimicrobials was lower than $90 \%$. The genotype prediction of phenotypic resistance to all antimicrobials, other than streptomycin (STR), had specificity greater than 91\% (Table 2).

\section{Association of AMR genes, plasmid replicons, and virulence genes with different Salmonella serotypes using WGS}

Serotypes were found to vary with regard to the presence/absence of AMR coding gene, plasmid replicon, and virulence gene using WGS approach based on the odds ratio to evaluate their associations (Table 3). Significant $(P<0.05)$ associations between $S$. Typhimurium and $S .4,[5], 12: \mathrm{i}:-$ with AMR genes were observed, including aadA25, sul1, tet $\mathrm{A}$, and tet $\mathrm{G}$, while the aadA1, $\operatorname{aad} \mathrm{A} 2$, tet $\mathrm{A}$, and tet $\mathrm{R}$ genes were found significantly associated with $S$. Derby (Table 3). On the other hand, 


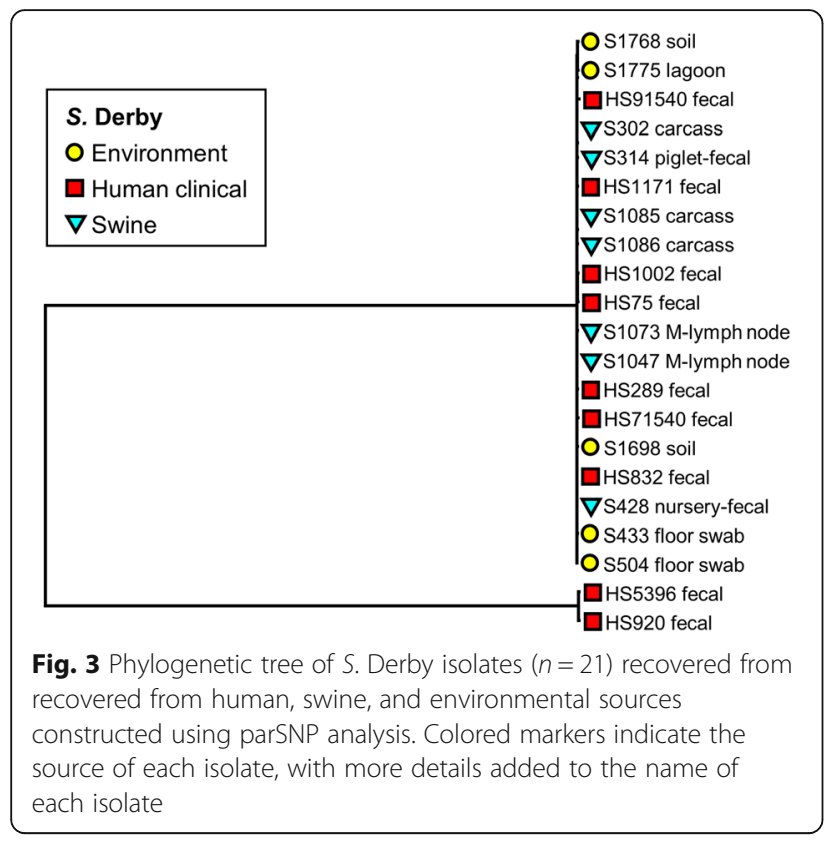

AMR genes including aph(3")-Ib, aph(6)-Id, strA, and strB were significantly detected in $S$. Schwarzengrund (Table 3). Several significant $(P<0.05)$ associations between plasmids and Salmonella serotypes were also observed, including IncFIB and IncFII in serotypes Typhimurium, 4,[5],12:i:-, and Schwarzengrund, while IncQ2 was significantly found in serotype Derby.

As highlighted previously, several major virulence genes were detected in all Salmonella isolates in our study (Additional file 2: Table S2). However, pefA, $s p v \mathrm{~B}$,

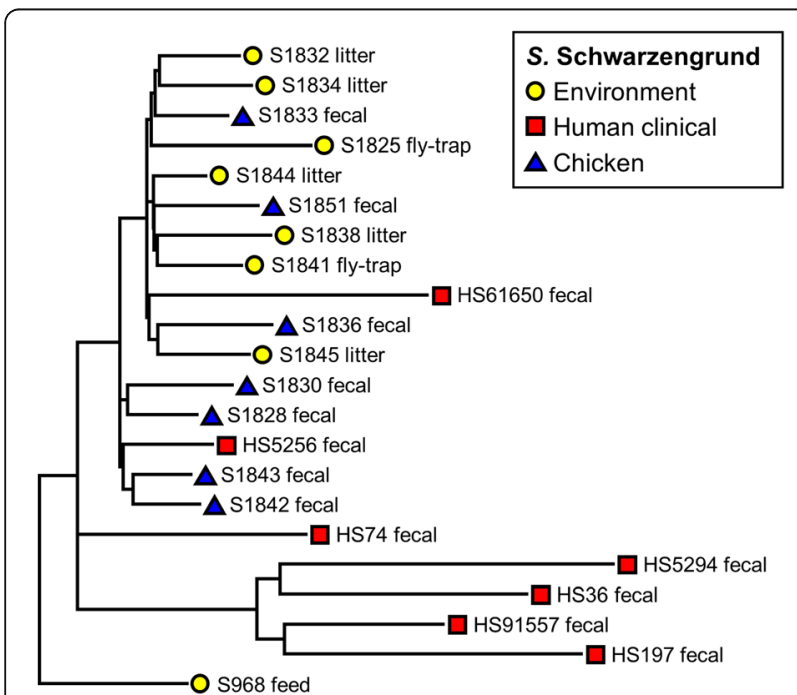

Fig. 4 Phylogenetic tree of S. Schwarzengrund isolates $(n=22)$ recovered from recovered from human, chicken, and environmental sources constructed using parSNP analysis. Colored markers indicate the source of each isolate, with more details added to the name of each isolate

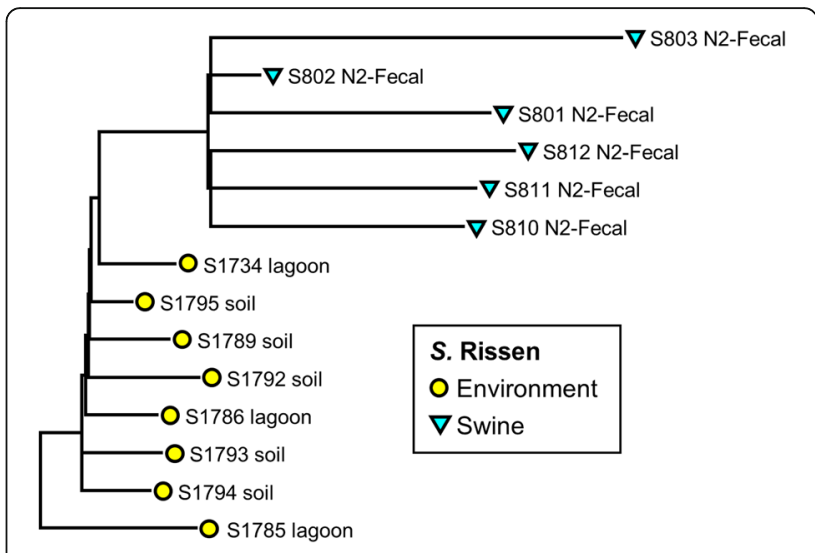

Fig. 5 Phylogenetic tree of S. Rissen isolates $(n=14)$ recovered from recovered from swine and environmental sources constructed using parSNP analysis. Colored markers indicate the source of each isolate, with more details added to the name of each isolate

and $s s p \mathrm{H} 1$ were specifically detected in serovar Typhimurium and 4,[5],12:i:- (Table 3). S. Schwarzengrund genomes were significantly associated with the presence of $c d t \mathrm{~B}$, iuc, and iut $\mathrm{A}$ genes, while gtr $\mathrm{A}$ and sse genes were significantly detected in $S$. Derby (Table 3 ).

\section{Discussion}

The objective of this study was to characterize Salmonella serovar, AMR determinants and virulence genes using whole genome sequencing. The 200 Salmonella enterica genomes were isolated from different sources of origin including human, swine, poultry, and environment, and were analyzed using the core genome SNP-based analysis and the alignment-free analysis method FFP. The phylogenetic trees obtained from parSNP and FFPry showed that the clusters observed matched Salmonella serovars (Fig. 1). The branch length in FFP-based trees is more representative of differences over the whole genome, which may be due to differential plasmid, prophage content, or other accessory genome [28], while SNP-based trees use the core genome derived from whole-genome alignment and read mapping for phylogeny construction $[27,28]$. The major difference of the SNP- and FFP-based analyses was in the order of the serovar clusters within the tree, however, the overall approach selected had relatively little effect on the topology of the phylogenetic trees (Fig. 1). A number of studies have reported the use of SNP-based analysis as a potential molecular subtyping tool for outbreak investigation in multiple Salmonella serovars including Dublin [29], Enteritidis [22, 30], Heidelberg [31], Manhattan [21], Montevideo [32, 33], and Typhimurium [34-36].

The phylogenetic analysis based on WGS-derived SNPs has been shown to provide greater cluster resolution than the gold standard subtyping method, pulsed-field gel electrophoresis (PFGE), resulting in discrimination of 

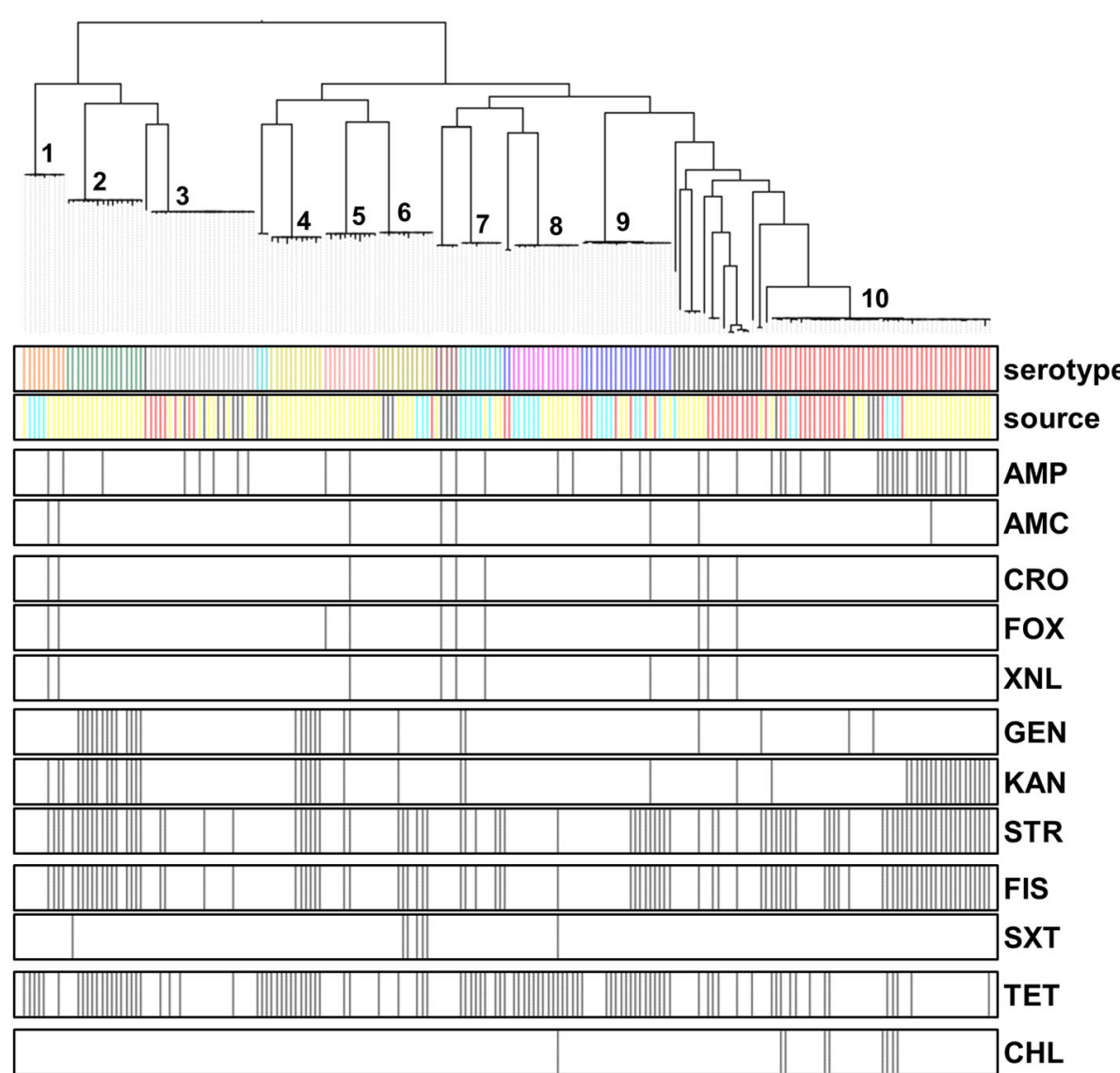

Fig. 6 Distribution of phenotypic antimicrobial resistance in the genomes of the 200 S. enterica isolates included in this study. The isolates were clustered based on core genome SNPs using ParSNP, and the antimicrobial resistances are shown by black lines in the respective bars below. Antimicrobials used are grouped according to their class and mechanism: penicillins (AMP, ampicillin; AMC, amoxicillin and clavulanate [augmentin, AUG]); cephalosporins (CRO, ceftriaxone (AXO); FOX, cefoxitin; XNL, ceftiofur); aminoglycosides (GEN, gentamicin; KAN, kanamycin; STR, streptomycin); sulfanomides/folate inhibitors (FIS, sulfisoxazole; SXT, trimetroprim and sulfamethoxazole); tetracycline (TET) and chloramphenicol (CHL). For source, these were subdivided into four major classes: environment (yellow), human clinical (red), chicken (dark blue) and swine (light blue). Major serovars are indicated by numbers: 1. Johannesburg; 2. Muenster; 3. Schwarzengrund; 4. Worthington; 5 . Altona; 6. Mbandaka; 7. Senftenberg; 8. Rissen; 9. Derby; 10. Typimurium and 4,[5],12:1-. Full details of source can be found in Additional file 2: Table S1

outbreak-related human clinical isolates and food or environmental origins [21-23]. ParSNP was run for all the 200 Salmonella genomes and separately for each of the serovars. Although the separate comparisons indeed increased the core genome component as would be predicted, this was not a major increase, and we do not expect that the removal of the outliers will have a significant effect on the trees. In concordance with those prior literatures, the current study found that the core genome SNP-based trees of individual Salmonella serovar including Typhimurium and 4,[5],12:i:- (Fig. 2), Schwarzengrund (Fig. 4), and Rissen (Fig. 5) were mostly clustered based on source of origin. However, there were some exceptions in each individual tree. As shown in Fig. 2, some clinical $S$. Typhimurium isolates (HS71549, HS51537, and HS51628) were closely related to the environmental, swine, and chicken isolates, respectively. The Schwarzengrund cluster in Fig. 4 showed that the Salmonella isolates from chicken feces clustered with the isolates obtained from environmental isolates which were derived from the same farm. There was no isolation source-dependent clustering in $S$. Derby (Fig. 3), with genomes from human, swine and environmental isolates clustering together. These findings can point towards the potential transmission of Salmonella among humans, animals and the environment and support the idea of zoonotic transmission, while independent human sub-clustering in each serovar might be referred to human-to-human transmission. However, the human Salmonella isolates included in our analysis were only from the North Carolina State Public Health Laboratory which might not be represent all the human clinical cases. According to the same timeline as human Salmonella outbreaks belonged to the independent human sub-clusters, the animal/environmental sources which may have a chance to group with those human sub-clusters were not scheduled for sampling. 
Table 2 Comparison between genotypic AMR prediction by WGS and phenotypic expression based on MIC levels of AMR Salmonella isolates $(n=200)$

\begin{tabular}{|c|c|c|c|c|c|c|c|c|}
\hline \multirow[t]{2}{*}{ Antimicrobials $^{a}$} & \multicolumn{2}{|c|}{ Resistant by phenotype } & \multicolumn{2}{|c|}{ Susceptible by phenotype } & \multirow{2}{*}{$\begin{array}{l}\text { Sensitivity } \\
(\%)\end{array}$} & \multirow{2}{*}{$\begin{array}{l}\text { Specificity } \\
(\%)\end{array}$} & \multirow{2}{*}{$\begin{array}{l}\mathrm{PPV}^{\mathrm{b}} \\
(\%)\end{array}$} & \multirow{2}{*}{$\begin{array}{l}\mathrm{NPV}^{\mathrm{C}} \\
(\%)\end{array}$} \\
\hline & WGS: AMR gene + & WGS: AMR gene - & WGS: AMR gene + & WGS: AMR gene - & & & & \\
\hline AMP & 36 & 7 & 4 & 153 & 83.72 & 97.45 & 90 & 95.63 \\
\hline AMC & 8 & 2 & 4 & 186 & 80 & 97.89 & 66.67 & 98.94 \\
\hline CRO & 9 & 1 & 3 & 187 & 90 & 98.42 & 75 & 99.47 \\
\hline FOX & 6 & 1 & 3 & 187 & 90 & 98.42 & 75 & 99.47 \\
\hline XNL & 6 & 1 & 3 & 187 & 90 & 98.42 & 75 & 99.47 \\
\hline GEN & 24 & 4 & 5 & 167 & 85.71 & 97.09 & 82.76 & 97.66 \\
\hline KAN & 37 & 9 & 9 & 145 & 80.43 & 94.16 & 80.43 & 94.08 \\
\hline STR & 98 & 17 & 10 & 75 & 85.22 & 88.24 & 90.74 & 81.52 \\
\hline FIS & 87 & 5 & 4 & 104 & 94.57 & 96.29 & 95.6 & 95.41 \\
\hline SXT & 6 & 1 & 1 & 192 & 85.71 & 99.48 & 85.71 & 99.48 \\
\hline TET & 93 & 9 & 8 & 90 & 91.18 & 91.84 & 94.9 & 88.24 \\
\hline $\mathrm{CHL}$ & 7 & 2 & 1 & 190 & 77.78 & 99.48 & 87.5 & 98.96 \\
\hline Overall & & & & & 87.61 & 97.13 & 88.35 & 96.93 \\
\hline
\end{tabular}

a ampicillin (AMP), amoxicillin/clavulanic acid (AMC), ceftriaxone (CRO), cefoxitin (FOX), Ceftiofur (XNL), gentamicin (GEN), kanamycin (KAN), streptomycin (STR), sulfisoxazole (FIS), trimethoprim/sulfamethoxazole (SXT), and tetracycline (TET), chloramphenicol (CHL)

${ }^{b}$ positive predictive value (PPV)

${ }^{c}$ negative predictive value (NPV)

In addition, $S .4,[5], 12:$ i:- has been defined as a monophasic variant of serovar Typhimurium because of their antigenic and genetic similarities, and the characterization of S. 4,[5],12:i:- using the typical molecular approaches revealed that $S$. Typhimurium is the direct ancestor of $S$. 4,[5],12:i:- [37]. Even the two serovars were clustered together (Fig. 2), parSNP-based subtyping could be a suitable analysis applied to differentiate these serovars. In contrast to $S$. Derby (Fig. 3), the sources of origin cannot be differentiated using parSNP analysis. This serovar has a highly homogeneous genetic composition and can be carried by different hosts [38]. Moreover, the MLST database (http://mlst.ucc.ie/mlst/mlst/dbs/Senterica/) indicates that Derby is a polyphyletic serovar, having originated from more than one common ancestor, and possesses several distantly related sequence types (ST) [39]. Thus
parSNP-based analysis might not be an appropriate method for this serovar. However, a recent study in China reported that the clustered regularly interspaced short palindromic repeats (CRISPRs) could be a useful subtyping tool for $S$. Derby in molecular epidemiological investigations [40]. Though the SNP typing is the reliable tool for genomic and epidemiologic studies, it is not without limitations. SNP-based analysis requires alignment of whole genome sequences and only utilizes the core genome, which may be less sensitive as a result. In addition, this method is still limited to the intragenus analysis of closely related species and strains $[27,41]$.

The FFP phylogenetic clustering is an effective tool that relies on an alignment-free approach for genomic evolution study. Unlike parSNP-based method which focuses on core genome, the phylogenetic trees acquired

Table 3 AMR determinant, plasmid replicon, and virulence gene detections based on WGS in Salmonella serotypes

\begin{tabular}{|c|c|c|c|}
\hline Characteristic: & S. Typhimurium \& S. 4,[5],12:i:- & S. Derby & S. Schwarzengrund \\
\hline$\overline{\text { AMR gene }(O R)^{a}}$ & $\begin{array}{l}\text { aadA25 (11.05) } \\
\text { sul1 }(2.18) \\
\text { tetA }(0.23) \\
\text { tetG }(\infty)\end{array}$ & $\begin{array}{l}\operatorname{aadA1}(4.22) \\
\operatorname{aadA2}(3.2) \\
\operatorname{tet} \mathrm{A}(4.57) \\
\operatorname{tet}(10.44)\end{array}$ & $\begin{array}{l}\text { aph(3")-Ib (48.9) } \\
\text { aph(6)-Id (25.25) } \\
\text { strA (48.9) } \\
\text { strB (40.48) }\end{array}$ \\
\hline Plasmid $(\mathrm{OR})^{\mathrm{a}}$ & $\begin{array}{l}\text { colRNAI (5.07) } \\
\text { IncFIB (8.4) } \\
\text { IncFII (10.51) }\end{array}$ & IncQ2 ( $\infty)$ & $\begin{array}{l}\text { IncFIB (7.22) } \\
\text { IncFIC (o) } \\
\text { IncFII (20.53) }\end{array}$ \\
\hline Virulence gene $(\mathrm{OR})^{\mathrm{a}}$ & $\begin{array}{l}\text { pefA (224) } \\
\text { spvB (268.24) } \\
\text { sspH1 (3.28) }\end{array}$ & $\begin{array}{l}\operatorname{gtrA}(5.38) \\
\text { sseJ/K1/L ( }) \\
\text { sseK2 }(4.5)\end{array}$ & $\begin{array}{l}\operatorname{cdtB}(\infty) \\
i u c A / B / C / D(92.27) \\
i u t A(92.27) \\
\operatorname{spvB}(0)\end{array}$ \\
\hline
\end{tabular}

${ }^{a}$ An odds ratio (OR) of 0 indicates the absence of that gene in a given Salmonella serotype, while the OR of infinity ( $\infty$ ) indicates that the mentioned gene was detected only in a specific serotype and none of the other serotypes

Only the odds ratios with $P$-value $<0.05$ are shown 
from FFP-based method are affected by recombinant genes and/or horizontal gene transfer including plasmid, prophage, and other accessory gene contents [28]. However, the main clustering structure is not significantly different (Fig. 1). The advantages of FFP-based analysis are that it is independent of a reference genome, and has lower hardware requirements. Additionally, FFP analysis can be performed with whole genome shotgun samples as it is not affected by contig orientation, and contig order [28]. FFP-based analyses has been reported in a number of bacterial genomic studies, including Helicobacter pylori [28], Bacillus spp. [42], Escherichia coli [43, 44], and Shigella [44]. These studies have revealed that the FFP method can contribute to the phylogenetic clusters based on geographic relation and outbreak detection, and could provide a complementary analysis approach. Our study is the first to utilize the alignment-free FFP analysis in Salmonella and compare it to the core genome SNP-based analysis. We found that the phylogenetic clusters from these methods were similar in term of serovar characterization, but the branching varied due to differences in analysis approaches (Fig. 1). While SNP- and MLST-based methods are likely to continue to be the default choice for subtyping and comparative genomics in Salmonella, the FFP method can serve as a useful alternative method requiring relatively low-powered computing resources [28].

Antimicrobials are reported extensively used in food animal production to treat clinical disease, to prevent and control common diseases, and to enhance animal growth [45]. Tetracycline and tylosin are frequently mixed in animal feed for disease prevention and growth promotion purposes in commercial swine and poultry systems $[45,46]$. In accordance to the high percentages of phenotypic tetracycline and sulfisoxazole resistance were reported in our result. The WGS revealed a number of tetracycline and sulfisoxazole resistance genes such as tet $A$, tet $B$, tetC, tet $R$, sull, and sul2 (Additional file 2: Table S2). Of interest, gene mechanisms of tetracycline resistance including the efflux genes, the ribosomal protection and enzymatic genes were suggesting a possible ecological role for specific wide spread of tetracycline resistance [47]. However, AMR genes especially tetracycline and sulfonamide were also detected in livestock production surrounding even when antimicrobial drugs were not administered to animals [47, 48].

In this study, we have shown that WGS is an excellent tool for accurately predicting antimicrobial resistant phenotype in human, animal, and environment associated multiple Salmonella serovars, as WGS predictions and phenotypic resistance matched well with high sensitivity and specificity in our study. Overall, the resulting resistance genotypes correlated with $87.61 \%$ sensitivity and $97.13 \%$ specificity to the resistance phenotype (Table 2).
Among the discordant results in our study, the lowest specificity of AMR prediction was observed for streptomycin which accounted for the presence of streptomycinresistance genes but lacked phenotypic resistance. This finding was in concordance with the previous studies in Salmonella $[24,49]$ and E. coli $[25,50]$. The streptomycin discrepancies have been commonly detected in other studies too because streptomycin is not used to treat enteric infections, and as such, results in the absence of precise clinical breakpoint for streptomycin susceptibility in Salmonella and E. coli [24]. Although the strA/strB and $\operatorname{aad} A$ genes were detected, the $\operatorname{str} A / \operatorname{str} B$ genes conferred higher resistance than aadA genes [25, 51]. Thus, the presence of aadA genes by in silico method may not result in streptomycin resistance phenotypically. In addition, the mechanism of streptomycin resistance is frequently due to lacking of the gene expression as well as mutations in the $16 \mathrm{~S}$ rRNA gene leading to difficulty of phenotypic prediction $[50,52]$. Our results suggest that the refinement of WGS-based AMR prediction could be beneficial and can definitely enhance the monitoring of AMR strains and determinants detected in humans, foods, animals, and environment.

The Salmonella serovars significantly correlated with the presence/absence of AMR genes, plasmid replicons, and virulence genes. We observed specific AMR genes in each Salmonella serovar (Table 3). This result along with the phylogenetic relatedness revealed that the type of serovar in discussion had the greatest impact on AMR characterization. Previous studies reported the presence of AMR genes has been shown to be primarily associated with a particular host and is not frequently transmitted among different species which in accordance to our finding (Additional file 2: Table S2) [20, 49]. Multiple plasmid replicons were detected in this study using WGS method (Additional file 2: Table S2). Plasmids were observed specific to Salmonella serovar that was very similar to the AMR genes (Table 3). This is in accordance to our previous study that the plasmid profiles were correlated to Salmonella serovar and incompatibility (Inc) groups [13]. The IncF (both FI and FII) family found across the different Salmonella serovars in our study is known to be a well-adapted and commonly distributed plasmid among members of the Enterobacterceae family $[53,54]$. Although our data cannot fully explain the transmission of AMR determinants among various species, they are in line with previous studies that reported on the role of animals and environment as important sources of multiple AMR genes as well as plasmids, and that transmission can occur by horizontal gene transfer $[13,55,56]$.

Multiple virulence genes were identified among the several Salmonella serovars across different sources by WGS (Additional file 2: Table S2). These genes have 
been described to be involved in several processes important for Salmonella transmission and infection, including adhesion, type III secretion system (T3SS), host recognition/invasion, filamentous formation, magnesium uptake, iron acquisition, and regulation of stress factors. Our data showed that Salmonella isolates recovered from animal or/and environmental sources contained the same virulence genes as carried by human clinical isolates. Along with the phylogenetic analysis, these findings support our view that the high frequency of virulence genes detected in food animal and environment may be transmitted and cause infections in humans, a suggestion that has been previously made in prior studies [57-59]. Figueira et al. (2013) reported that the lack of sseJ, a particular virulence gene makes $S$. Typhimurium strain became more heterogenous [60]. In our study, this gene was only present in $S$. Derby (Table 3 ) which may relate to the non-source-dependent clustering found in this homogenous serovar as mentioned previously (Fig. 3). One of the typhoid-associated virulence factors, the cytolethal distending toxin $c d t B$, was detected in all isolates of Schwarzengrund, Johannesburg, and Muenster (Additional file 2: Table S2), which was similar to a previous study that detected this gene in $S$. Schwarzengrund [61]. The $c d t B$ encodes the typhoid toxins of $S$. Typhi and is not reported from a wider distribution among non-typhoidal Salmonella serovars (NTS) $[57,61]$. However, there were a few reports of the prevalence of this virulence gene in several NTS, including Javiana [57], Montevideo, Schwarzengrund, and Bredeney [61]. This data suggested that the $c d t B$ toxin may contribute to the pathogenicity in human and animal.

\section{Conclusions}

WGS is a helpful tool to assess the phylogenetic relations among multiple serotypes, AMR and virulenuce gene evaluation and assist in the molecular epidemiological studies of foodborne pathogens. The SNP-based and FFP-based analysis provided the higher resolution Salmonella phylogenetic trees that could differentiate the isolates recovered from human, animal, and environment. In addition, WGS is a useful tool for AMR prediction, plasmid replicon, and virulence gene detections. Our study shows the close relationship between Salmonella isolates associated with different hosts, which is supportive of possible zoonotic transmission. This is seen among multiple serotypes, and the prevalence of AMR genes, plasmid replicons and virulence genes that were identical in different species and could potentially highlight exchange of serovars across different hosts.

\section{Methods}

\section{Salmonella isolates selection}

The 200 Salmonella isolates included are from multiple serovars collected from multiple sources, including human, swine, poultry, and agricultural environment, and used for WGS (Table 1). The serovars were selected across multiple time points between the years 2009-2016. The human Salmonella isolates were from stool samples from clinical cases received from the North Carolina State Public Health Laboratory $(n=44)$. Swine isolates $(n=32)$ originated from fecal, lymph nodes, and carcass swab samples from commercial farms in North Carolina, while poultry isolates $(n=22)$ were from chicken fecal samples collected from sustainable farms in North Carolina and Tennessee. Environmental isolates $(n=102)$ were collected from commercial farms and sustainable farms in $\mathrm{NC}$ and $\mathrm{TN}$. The list of isolates and details were tabulated in Additional file 2: Table S1. All samples were stored in Brucella broth at $-80^{\circ} \mathrm{C}$ until further characterization.

\section{Phenotypic antimicrobial resistance testing}

The antimicrobial susceptibility and the minimum inhibitory concentration (MIC) profile of each Salmonella isolate was determined by the broth microdilution method using the gram-negative Sensititre ${ }^{\text {min }}$ (CMV3AGNF) plate (Trek Diagnostic Systems, OH) in accordance with the guidelines and interpretations published by the Clinical and Laboratory Standards Institute (CLSI) $[62,63]$ and National Antimicrobial Resistance Monitoring System (NARMS) [64]. The panel of 15 antimicrobials tested include amoxicillin/clavulanic acid (AMC, suppliers abbreviation AUG; 1/0.5-32/16 $\mu \mathrm{g} / \mathrm{ml}$; breakpoint $\geq 32 / 16$ ), ampicillin (AMP; $1-32 \mu \mathrm{g} / \mathrm{ml}$; breakpoint $\geq 32$ ), azithromycin (AZI; $0.12-16 \mu \mathrm{g} / \mathrm{ml}$; breakpoint $\geq 32$ ), cefoxitin (FOX; $0.5-32 \mu \mathrm{g} / \mathrm{ml}$; breakpoint $\geq 32$ ), ceftiofur (XNL; $0.12-8 \mu \mathrm{g} / \mathrm{ml}$; breakpoint $\geq 8$ ), ceftriaxone (CRO, suppliers abbreviation AXO; 0.25-64 $\mu \mathrm{g} / \mathrm{ml}$; breakpoint $\geq 4$ ), chloramphenicol (CHL; 2-32 $\mu \mathrm{g} / \mathrm{ml}$; breakpoint $\geq 32$ ), ciprofloxacin (CIP; 0.015-4 $\mu \mathrm{g} / \mathrm{ml}$; breakpoint $\geq 4$ ), gentamicin (GEN; $0.25-16 \mu \mathrm{g} / \mathrm{ml}$; breakpoint $\geq 16$ ), kanamycin (KAN; $8-64 \mu \mathrm{g} / \mathrm{ml}$; breakpoint $\geq 64$ ), nalidixic acid (NAL; $0.5-$ $32 \mu \mathrm{g} / \mathrm{ml}$; breakpoint $\geq 32$ ), streptomycin (STR; 2-64 $\mu \mathrm{g} /$ $\mathrm{ml}$; breakpoint $\geq 32$ ), sulfisoxazole (FIS; $16-256 \mu \mathrm{g} / \mathrm{ml}$; breakpoint $\geq 256$ ), trimetroprim/sulfamethoxazole (SXT; $0.12 / 2.38-4 / 76 \mu \mathrm{g} / \mathrm{ml}$; breakpoint $\geq 4 / 76$ ), and tetracycline (TET; $4-32 \mu \mathrm{g} / \mathrm{ml}$; breakpoint $\geq 16$ ). E. coli ATCC25922 was used as internal quality control. The Salmonella isolates with MICs in the intermediate level were categorized into susceptible to avoid overestimation of resistance.

\section{Genome library preparation and sequence assembly}

The Salmonella isolates $(n=200)$ were cultured overnight at $37{ }^{\circ} \mathrm{C}$ on Luria-Bertani (LB) agar. Genomic DNA were extracted using DNeasy blood and tissue kit 
(Qiagen, CA). DNA concentrations were quantitated using the Qubit 4.0 Fluorometer for double-strand-DNA high-sensitivity assay kit (Thermo Fisher Scientific, MA). Genomic libraries were prepared using the Nextera XT kit (Illumina, CA) for multiplexed sequencing. WGS were performed on the Illumina MiSeq platform with 2*250 bp paired-end (PE) reads (MiSeq reagent kit, version 3). Genomes were assembled using SPAdes 3.10 .1 [65], with contigs $<200 \mathrm{bp}$ and coverage $<10$-fold excluded from downstream analyses. The assemblies were checked for quality parameters (genome size, largest contig, N50 and L50 values) using QUAST v. 4.5 [66].

\section{Salmonella serotyping and Salmonella in silico typing resource (SISTR)}

The animal and environmental Salmonella isolates were initially sent to the National Veterinary Services Laboratories (NVSL) at Ames, Iowa for serotyping using the Kauffman-White scheme, while the human serotyping was conducted at the North Carolina State Public Health Laboratory. All 200 Salmonella genomes were analyzed using the Salmonella in silico Typing Resource (SISTR) software (https:// lfz.corefacility.ca/sistr-app/) for serovar prediction. The SISTR module utilizes $\mathrm{O}$ (somatic) antigen, $\mathrm{H}$ (flagellar: H1 and H2) antigen, and/or serogroup-specific probes particularly designed for Salmonella Genoserotyping Array (SGSA) [26]. The results from SISTR interpretation were compared to the traditional Kauffman-White serotyping. The serovar prediction was confirmed by phylogenetic analysis using core genome parSNPs and FFP analysis as described below.

\section{Alignment-free feature frequency profiling and core genome SNPs analysis}

The 200 Salmonella genomes were identified for core genome SNPs and were clustered using the ParSNP program from the Harvest suite [27], using the "-a 13" and "-x" settings [28], which respectively invoke a smaller (a)NCHOR window for higher resolution mapping [27], and the PhiPack module, which excludes SNPs located in regions of recombination. For the parSNP tree shown in Fig. 1, a random genome was selected from the 200 genomes using the "-r!" switch. In addition, trees were generated using a single representative of 11 serovars, which did not result in noticeable differences in tree topology (data not shown). An alignment-free feature frequency profiling using purine-pyrimidine words (FFPry) was performed with the FFP version 3.19 suite of programs (http://sourceforge.net/projects/ ffp-phylogeny/) [67, 68], utilizing the FFPry generated phylogenetic tree [28]. Treegraph v2 [69] and Figtree (http://tree.bio.ed.ac.uk/software/figtree/) were used to annotate and visualize the phylogenetic trees.

Determination of Salmonella virulence, plasmid replicons, and antimicrobial susceptibility determinants

The genotyping by in silico method for 200 Salmonella sequences were done by annotating assembled genomes via Prokka v1.12 [70]. The contigs were submitted to PlasmidFinder [71], and ResFinder [72] modules to determine the existing plasmid replicon types, and AMR genes, respectively. Virulence genes were identified with an in-house workflow using SRST2 v0.1.4.5 [73]. The Illumina raw reads were mapped against chromosomal and plasmid virulence genes found in the Virulence Factor Database for Salmonella (VFDB) which currently contains 2017 genes database associated with virulence in Salmonella [http://www.mgc.ac.cn/VFs/status.htm] [74]. Finally, the presence/absence of AMR determinants, plasmid replicons, and virulence genes were calculated for association with Salmonella serotype using odds ratios along with Chi-square test or Fisher's exact test with the $P$-value level $<0.05$ of significance. All statistical analysis was carried out using $\mathrm{R}$ version 3.1.2 ( $\mathrm{R}$ foundation for statistical computing, Vienna, Austria).

\section{Correlation of susceptibility phenotypes and genotypes}

All phenotypic characters were generated from the 200 Salmonella isolates by broth microdilution (Sensititre $^{\mathrm{TM}}$ ) antimicrobial susceptibility testing previously described. Each interpretation of resistant or susceptible to a given antimicrobial drug were compared to the presence or absence of known corresponding resistance genes and/or specific structural gene mutations detected by the WGS. The percentage of correlation between resistant phenotypes and genotypes were calculated. The phenotypic results were counted as the reference outcome, sensitivity was calculated by dividing the number of isolates that were genotypically resistant by the total number of isolates exhibiting clinical resistant phenotypes. Specificity was also calculated by dividing the number of isolates that were genotypically susceptible by the total number of isolates with susceptible phenotypes. The percentages of positive predictive values (PPV) and negative predictive values (NPV) were calculated as well.

\section{Accession numbers}

Paired-end reads for the 200 Salmonella isolates in this study have been deposited in the National Center for Biotechnology Information (NCBI)'s under the Bioproject accession number PRJNA293224. Individual Sequence Read Archive (SRA) accession numbers have been tabulated in Additional file 2: Table S1. 


\section{Additional files}

Additional file 1: Figure S1. Distribution of phenotypic antimicrobial resistance of Salmonella isolates based on FFPry. (TIF $1823 \mathrm{~kb}$ )

Additional file 2: Table S1. Salmonella isolates that were sequenced and constructed for this research. Table S2. AMR, plasmid, and virulence genes. (XLSX $253 \mathrm{~kb}$ )

\section{Abbreviations}

AMC, AUG: amoxicillin/clavulanic acid; AMP: Ampicillin; AMR: Antimicrobial resistance; AZI: Azithromycin; CHL: Chloramphenicol; CIP: Ciprofloxacin; CRISPR: Clustered regularly interspaced short palindromic repeats; $C R O$, AXO: Ceftriaxone; FFP: Feature frequency profiling; FIS: Sulfisoxazole; FOX: Cefoxitin; GEN: Gentamicin; KAN: Kanamycin; MCR: Plasmid-mediated colistin resistance; MDR: Multidrug resistant; MIC: Minimum inhibitory concentration; MLST: Multilocus sequence typing; MLVA: Multilocus variablenumber tandem repeat analysis; NAL: Nalidixic acid; NPV: Negative predictive value; NTS: Non-typhoidal Salmonella; PFGE: Pulsed-field gel electrophoresis; PPV: Positive predictive value; SNP: Single nucleotide polymorphism; STR: Streptomycin; SXT: Trimetroprim/sulfamethoxazole; TET: Tetracycline; WGS: Whole genome sequencing; XNL: Ceftiofur

\section{Acknowledgements}

We gratefully appreciate the swine and poultry producers in the state of NC and TN for allowing access to their farms for collecting the animal, manure and environmental samples. We acknowledge the North Carolina State Public Health Laboratory for providing Salmonella human clinical isolates. This study would not have been possible without their cooperation and support. We thank Joy Horovitz for generating the WGS profile of the Salmonella isolates.

\section{Funding}

This project was funded by the National Pork Board grant (NPB-556678), Center for Produce Safety grant (CPS-201400969-01) and the College of Veterinary Medicine, North Carolina State University. Additionally, the authors would like to thank the Engineering and Physical Sciences Research Council (EPSRC) grant for providing collaborative opportunities and a travel grant to Dr. Thakur. The funding agencies did not contribute to the study design, data collection, analysis and interpretation of the data in writing the manuscript. It was done independently by the investigators.

\section{Availability of data and materials}

The Salmonella WGS data have been deposited to NCBI (Bioproject accession number: PRJNA293224).

\section{Authors' contributions}

SP: She contributed to generation of WGS data and its analysis. She also wrote the manuscript. AV: He contributed in WGS data analysis and manuscript editing. ST: He was the PI of the grant that funded the study and he was involved in data analysis, manuscript editing and submission.

\section{Ethics approval and consent to participate}

The human patients from whom Salmonella was recovered were completely anonymous and even after all the analysis and tests, the human sample still remained anonymous. As such, the NC State IRB (FWA: 00003429) indicated the study research did not need IRB approval because it does not meet the definition for human subjects research. Salmonella isolated from food animals in this study were approved by NC. State University application for vertebrate animal use IACUC \# 08-031-A.

\section{Consent for publication}

Not applicable.

\section{Competing interests}

The authors declare that they have no competing interests.

\section{Publisher's Note}

Springer Nature remains neutral with regard to jurisdictional claims in published maps and institutional affiliations.

\section{Author details}

${ }^{1}$ Faculty of Veterinary Medicine, Rajamangala University of Technology Tawan-ok, Chonburi, Thailand. ${ }^{2}$ School of Veterinary Medicine, Faculty of Health and Medical Sciences, University of Surrey, Surrey, UK. ${ }^{3}$ Department of Population Health and Pathobiology, College of Veterinary Medicine, North Carolina State University, Raleigh, NC, USA. ${ }^{4}$ Comparative Medicine Institute, North Carolina State University, Raleigh, NC, USA.

Received: 22 May 2018 Accepted: 2 October 2018

Published online: 06 November 2018

\section{References}

1. Centers for Disease Control and Prevention. Antibiotic resistance threats in the United States. CDC. 2013. http://www.cdc.gov/drugresistance/pdf/arthreats-2013-508.pdf. [Accessed Aug 2017].

2. Medalla F, Gu W, Mahon BE, Judd M, Folster J, Griffin PM, Hoekstra RM. Estimated incidence of antimicrobial drug-resistant nontyphoidal Salmonella infections, United States, 2004-2012. Emerg Infect Dis. 2017; 23(1):29.

3. European Centre for Disease Prevention and Control. Salmonellosis Annual Epidemiological Report 2016 [2014 data]. ECDC. https://ecdc. europa.eu/sites/portal/files/documents/Salmonellosis-aer-2014.pdf. [Accessed Aug 2017].

4. U.S. Department of Health and Human Services. Food safety. HHS, Washington, DC. https://www.healthypeople.gov/2020/topics-objectives/ topic/food-safety/national-snapshot. [Accessed Aug 2017].

5. Doumith $M$, Godbole G, Ashton P, Larkin L, Dallman T, Day M, Day M, Muller-Pebody B, Ellington MJ, de Pinna E, et al. Detection of the plasmidmediated mcr-1 gene conferring colistin resistance in human and food isolates of Salmonella enterica and Escherichia coli in England and Wales. J Antimicrob Chemother. 2016;71(8):2300-5.

6. Webb HE, Granier SA, Marault M, Millemann Y, den Bakker HC, Nightingale KK, Bugarel M, Ison SA, Scott HM, Loneragan GH. Dissemination of the mcr1 colistin resistance gene. Lancet Infect Dis. 2016;16(2):144-5.

7. Holmes AH, Moore LS, Sundsfjord A, Steinbakk M, Regmi S, Karkey A, Guerin $P J$, Piddock LJ. Understanding the mechanisms and drivers of antimicrobial resistance. Lancet. 2016:387(10014):176-87.

8. Helke KL, McCrackin MA, Galloway AM, Poole AZ, Salgado CD, Marriott BP. Effects of antimicrobial use in agricultural animals on drug-resistant foodborne salmonellosis in humans: a systematic literature review. Crit Rev Food Sci Nutr. 2017:57(3):472-88.

9. World Health Organization. Critically important antimicrobials for human medicine: ranking of antimicrobial agents for risk management of antimicrobial resistance due to non-human use: WHO; 2017. http://apps. who.int/iris/handle/10665/255027.

10. Finley RL, Collignon P, Larsson DJ, McEwen SA, Li XZ, Gaze WH, Reid-Smith $\mathrm{R}$, Timinouni M, Graham DW, Topp E. The scourge of antibiotic resistance: the important role of the environment. Clin Infect Dis. 2013;57(5):704-10.

11. Doyle MP, Erickson MC. Opportunities for mitigating pathogen contamination during on-farm food production. Int J Food Microbiol. 2012; 152(3):54-74

12. Pornsukarom S, Thakur S. Assessing the impact of manure application in commercial swine farms on the transmission of antimicrobial resistant Salmonella in the environment. PLoS One. 2016;11:e0164621.

13. Pornsukarom S, Thakur S. Horizontal dissemination of antimicrobial resistance determinants in multiple Salmonella serotypes following isolation from the commercial swine operation environment after manure application. Appl Environ Microbiol. 2017;83:e01503-17.

14. Wagenaar JA, Hendriksen RS, Carrique-Mas J. Practical considerations of surveillance of Salmonella serovars other than Enteritidis and typhimurium. Rev Sci Tech. 2013:32:509-19.

15. Keelara S, Scott HM, Morrow WM, Hartley CS, Griffin DL, Gebreyes WA Thakur S. Comparative phenotypic and genotypic characterization of temporally related nontyphoidal Salmonella isolated from human clinical cases, pigs, and the environment in North Carolina. Foodborne Pathog Dis. 2014;11(2):156-64

16. Centers for Disease Control and Prevention. National Salmonella Surveillance Annual Report, 2013. Atlanta: US Department of Health and Human Services, CDC; 2016

17. United States Department of Agriculture, Food Safety and Inspection Service. Serotypes Profile of Salmonella Isolates from Meat and Poultry 
Products, January 1998 through December 2014. USDA, FSIS. https:// www.fsis.usda.gov/wps/wcm/connect/3866026a-582d-4f0e-a8ce851 b39c7390f/Salmonella-Serotype-Annual-2014.pdf?MOD=AJPERES [Accessed Sept 2017].

18. Elnekave E, Hong S, Davies P, Alvarez J. Emerging Salmonella isolated from Midwest swine: ADM; 2018.

19. Achtman M, Wain J, Weill FX, Nair S, Zhou Z, Sangal V, Krauland MG, Hale $\mathrm{J}$, Harbottle $H$, Uesbeck A, et al. Multilocus sequence typing as a replacement for serotyping in Salmonella enterica. PLoS Pathog. 2012;8(6): e1002776.

20. Mather AE, Reid SW, Maskell DJ, Parkhill J, Fookes MC, Harris SR, Brown DJ, Coia JE, Mulvey MR, Gilmour MW, et al. Distinguishable epidemics of multidrug-resistant Salmonella typhimurium DT104 in different hosts. Science. 2013;341:1514-7.

21. Scaltriti E, Sassera D, Comandatore F, Morganti M, Mandalari C, Gaiarsa S, Bandi C, Zehender G, Bolzoni L, Casadei G, et al. Differential single nucleotide polymorphism-based analysis of an outbreak caused by Salmonella enterica serovar Manhattan reveals epidemiological details missed by standard pulsed-field gel electrophoresis. J Clin Microbiol. 2015; 53(4):1227-38.

22. Taylor AJ, Lappi V, Wolfgang WJ, Lapierre P, Palumbo MJ, Medus C, Boxrud D. Characterization of foodborne outbreaks of Salmonella enterica serovar Enteritidis with whole-genome sequencing single nucleotide polymorphism-based analysis for surveillance and outbreak detection. J Clin Microbiol. 2015:53:3334-40.

23. Leekitcharoenphon P, Nielsen EM, Kaas RS, Lund O, Aarestrup FM. Evaluation of whole genome sequencing for outbreak detection of Salmonella enterica. PLoS One. 2014;9(2):e87991.

24. McDermott PF, Tyson GH, Kabera C, Chen Y, Li C, Folster JP, Ayers SL, Lam C, Tate HP, Zhao S. Whole-genome sequencing for detecting antimicrobial resistance in nontyphoidal Salmonella. Antimicrob Agents Chemother. 2016; 60(9):5515-20.

25. Tyson GH, McDermott PF, Li C, Chen Y, Tadesse DA, Mukherjee S, BodeisJones S, Kabera C, Gaines SA. Loneragan GHet al. WGS accurately predicts antimicrobial resistance in Escherichia coli. J Antimicrob Chemother. 2015; 70(10):2763-9.

26. Yoshida CE, Kruczkiewicz P, Laing CR, Lingohr EJ, Gannon VP, Nash JH, Taboada EN. The Salmonella in silico typing resource (SISTR): an open webaccessible tool for rapidly typing and subtyping draft Salmonella genome assemblies. PLoS One. 2016;11(1):e0147101.

27. Treangen TJ, Ondov BD, Koren S, Phillippy AM. The harvest suite for rapid core-genome alignment and visualization of thousands of intraspecific microbial genomes. Genome Biol. 2014;15(11):524.

28. van Vliet AH, Kusters JG. Use of alignment-free phylogenetics for rapid genome sequence-based typing of Helicobacter pylori virulence markers and antibiotic susceptibility. J Clin Microbiol 2015;53(9):2877-2888

29. Mohammed M, Delappe N, O'connor J, McKeown P, Garvey P, Cormican M. Whole genome sequencing provides an unambiguous link between Salmonella Dublin outbreak strain and a historical isolate. Epidemiol Infect. 2016;144(3):576-81.

30. den Bakker HC, Allard MW, Bopp D, et al. Rapid whole-genome sequencing for surveillance of Salmonella enterica serovar Enteritidis. Emerg Infect Dis. 2014;20(8):1306

31. Hoffmann M, Zhao S, Pettengill J, Brown EW, Fontana J, labal Z, Kinney A, Limberger R, Musser KA, Shudt M, et al. Comparative genomic analysis and virulence differences in closely related Salmonella enterica serotype Heidelberg isolates from humans, retail meats, and animals. Genome biology and evolution. 2014;6(5):1046-68.

32. den Bakker HC, Switt Al, Cummings CA, Hoelzer K, Degoricija L, RodriguezRivera LD, Wright EM, Fang R, Davis M, Root T, et al. A whole-genome single nucleotide polymorphism-based approach to trace and identify outbreaks linked to a common Salmonella enterica subsp. enterica serovar Montevideo pulsed-field gel electrophoresis type. Appl Environ Microbiol. 2011;77(24):8648-55

33. Allard MW, Luo Y, Strain E, Li C, Keys CE, Son I, Stones R, Musser SM, Brown EW. High resolution clustering of Salmonella enterica serovar Montevideo strains using a next-generation sequencing approach. BMC Genomics. 2012:13(1):32.

34. Fu S, Octavia S, Tanaka MM, Sintchenko V, Lan R. Defining the core genome of Salmonella enterica serovar typhimurium for genomic surveillance and epidemiological typing. J Clin Microbiol. 2015;53(8):2530-8.
35. Alexander DC, Fitzgerald SF, DePaulo R, Kitzul R, Daku D, Levett PN, Cameron AD. Laboratory-acquired infection with Salmonella enterica serovar typhimurium exposed by whole-genome sequencing. J Clin Microbiol. 2016:54(1):190-3.

36. Ashton PM, Owen SV, Kaindama L, Rowe WPM, Lane CR, Larkin L, Nair S, Jenkins $C$, de Pinna EM, Feasey NA, et al. Public health surveillance in the UK revolutionises our understanding of the invasive Salmonella typhimurium epidemic in Africa. Genome medicine. 2017;9:92.

37. Soyer Y, Switt AM, Davis MA, Maurer J, McDonough PL, Schoonmaker-Bopp DJ, Dumas NB, Root T, Warnick LD, Gröhn YT, Wiedmann M. Salmonella enterica serotype 4, 5, 12: i:-, an emerging Salmonella serotype that represents multiple distinct clones. J Clin Microbiol. 2009;47(11):3546-56.

38. Kerouanton A, Rose V, Weill FX, Granier SA, Denis M. Genetic diversity and antimicrobial resistance profiles of Salmonella enterica serotype Derby isolated from pigs, pork, and humans in France. Foodborne Pathog Dis. 2013;10(11):977-84.

39. Hauser E, Hebner F, Tietze E, Helmuth R, Junker E, Prager R, Schroeter A Rabsch W, Fruth A, Malorny B. Diversity of Salmonella enterica serovar Derby isolated from pig, pork and humans in Germany. Int J Food Microbiol. 2011; 151(2):141-9.

40. Zheng H, Hu Y, Li Q, Tao J, Cai Y, Wang Y, Li J, Zhou Z, Pan Z, Jiao X. Subtyping Salmonella enterica serovar Derby with multilocus sequence typing (MLST) and clustered regularly interspaced short palindromic repeats (CRISPRs). Food Control. 2017;73:474-84.

41. Gardner SN, Hall BG. When whole-genome alignments just won't work: kSNP V2 software for alignment-free SNP discovery and phylogenetics of hundreds of microbial genomes. PLoS One. 2013;8(12):e81760.

42. Wang A, Ash GJ. Whole genome phylogeny of Bacillus by feature frequency profiles (FFP). Sci Rep. 2015;5:13644.

43. Cheung MK, Li L, Nong W, Kwan HS. 2011 German Escherichia coli O104:H4 outbreak: whole-genome phylogeny without alignment. BMC Res Notes. 2011;4(1):533.

44. Sims GE, Kim SH. Whole-genome phylogeny of Escherichia coli/Shigella group by feature frequency profiles (FFPs). Proc Natl Acad Sci. 2011; 108(20):8329-34.

45. Landers TF, Cohen B, Wittum TE, Larson EL. A review of antibiotic use in food animals: perspective, policy, and potential. Public Health Rep. 2012; 127(1):4-22.

46. Department of Agriculture (US). Swine 2006 part III: reference of swine health, productivity, and general management in the United States, 2006. Fort Collins: USDA, Animal and Plant Health Inspection Service, Veterinary Services, National Animal Health Monitoring System; 2008. http://www. aphis.usda.gov/animal_health/nahms/swine/downloads/swine2006/ Swine2006_dr_Partlll.pdf. [Accessed Mar 2018].

47. Cadena M, Durso LM, Miller DN, Waldrip HM, Castleberry BL, Drijber RA, Wortmann C. Tetracycline and Sulfonamide Antibiotic Resistance Genes in Soils from Nebraska Organic Farming Operations. Front Microbiol. 2018;9: fmicb.2018.01283.

48. Sancheza HM, Echeverria C, Thulsiraj V, Zimmer-Faust A, Flores A, Laitz M, Healy G, Mahendra S, Paulson SE, Zhu Y, Jay JA. Antibiotic resistance in airborne bacteria near conventional and organic beef cattle farms in California, USA. Water. Air, Soil Pollution. 2016;227(8):280.

49. Carroll LM, Wiedmann M, den Bakker H, Siler J, Warchocki S, Kent D, Lyalina S, Davis M, Sischo W, Besser T, et al. Whole-genome sequencing of drugresistant Salmonella enterica isolates from dairy cattle and humans in New York and Washington states reveals source and geographic associations. Appl Environ Microbiol. 2017;83(12):e00140-17.

50. Davis MA, Besser TE, Orfe LH, Baker KN, Lanier AS, Broschat SL, New D, Call DR. Genotypic-phenotypic discrepancies between antibiotic resistance characteristics of Escherichia coli from calves in high and low antibiotic use management settings. Appl Environ Microbiol. 2011;77(10):3293-9.

51. Garcia-Migura L, Sunde M, Karlsmose S, Veldman K, Schroeter A, Guerra B, Granier SA, Perrin-Guyomard A, Gicquel-Bruneau M, Franco A, et al. Establishing streptomycin epidemiological cut-off values for Salmonella and Escherichia coli. Microb Drug Resist. 2012;18(1):88-93.

52. Springer B, Kidan YG, Prammananan T, Ellrott K, Böttger EC, Sander P. Mechanisms of streptomycin resistance: selection of mutations in the 165 rRNA gene conferring resistance. Antimicrob Agents Chemother. 2001; 45(10):2877-84

53. Wang J, Stephan R, Karczmarczyk M, Yan Q, Hächler H, Fanning S. Molecular characterization of blaESBL-harboring conjugative plasmids identified in 
multi-drug resistant Escherichia coli isolated from food-producing animals and healthy humans. Front Microbiol. 2013;4.

54. Williams LE, Wireman J, Hilliard VC, Summers AO. Large plasmids of Escherichia coli and Salmonella encode highly diverse arrays of accessory genes on common replicon families. Plasmid. 2013;69(1):36-48.

55. Keelara S, Thakur S. Dissemination of plasmid-encoded AmpC $\beta$-lactamases in antimicrobial resistant Salmonella serotypes originating from humans, pigs and the swine environment. Vet Microbiol. 2014;173(1):76-83.

56. Edirmanasinghe R, Finley R, Parmley EJ, Avery BP, Carson C, Bekal S, Golding G, Mulvey MR. A whole genome sequencing approach to study Cefoxitinresistant Salmonella enterica serovar Heidelberg from various sources. Antimicrob Agents Chemother. 2017;61(4):AAC-01919.

57. Mezal EH, Stefanova R, Khan AA. Isolation and molecular characterization of Salmonella enterica serovar Javiana from food, environmental and clinical samples. Int J Food Microbiol. 2013;164(1):113-8.

58. Almeida F, Medeiros MI, Kich JD, Falcão JP. Virulence-associated genes, antimicrobial resistance and molecular typing of Salmonella typhimurium strains isolated from swine from 2000 to 2012 in Brazil. J Appl Microbiol. 2016;120(6):1677-90.

59. Borah PP, Borah P, Kalita P, Hussain I. Serotyping and detection of virulence genes of Salmonella isolates from man and animals by polymerase chain reaction. Indian Vet J. 2016;93(10):52-4.

60. Figueira $\mathrm{R}$, Watson $\mathrm{KG}$, Holden DW, Helaine S. Identification of Salmonella pathogenicity island-2 type III secretion system effectors involved in intramacrophage replication of $S$. enterica serovar typhimurium: implications for rational vaccine design. MBio. 2013:4(2):e00065-13.

61. Suez J, Porwollik S, Dagan A, Marzel A, Schorr YI, Desai PT, Agmon V, McClelland M, Rahav G, Gal-Mor O. Virulence gene profiling and pathogenicity characterization of non-typhoidal Salmonella accounted for invasive disease in humans. PLoS One. 2013;8(3):e58449.

62. Clinical and Laboratory Standards Institute. Performance standards for antimicrobial disk and dilution susceptibility tests for bacteria isolated from animals. 3rd ed. Wayne: CLSI supplement VET01S. CLSI; 2015.

63. Clinical and Laboratory Standards Institute. Performance standards for antimicrobial disc susceptibility test; approved standard. 10th ed. Wayne: CLSI document M02-A10. CLSl; 2013.

64. Food and Drug Administration. National antimicrobial resistance monitoring system—enteric bacteria (NARMS): 2009 executive report. Silver Spring: U.S. Department of Health and Human Services, FDA; 2011.

65. Bankevich A, Nurk S, Antipov D, Gurevich AA, Dvorkin M, Kulikov AS, Lesin VM, Nikolenko SI, Pham S, Prjibelski AD, et al. SPAdes: a new genome assembly algorithm and its applications to single-cell sequencing. J Comput Biol. 2012;19(5):455-77.

66. Gurevich A, Saveliev V, Vyahhi N, Tesler G. QUAST: quality assessment tool for genome assemblies. Bioinformatics. 2013;29(8):1072-5.

67. Sims GE, Jun SR, Wu GA, Kim SH. Alignment-free genome comparison with feature frequency profiles (FFP) and optimal resolutions. Proc Natl Acad Sci. 2009:106:2677-82

68. Jun SR, Sims GE, Wu GA, Kim SH. Whole-proteome phylogeny of prokaryotes by feature frequency profiles: an alignment-free method with optimal feature resolution. Proc Natl Acad Sci. 2010;107(1):133-8.

69. Stover BC, Muller KF. TreeGraph 2: combining and visualizing evidence from different phylogenetic analyses. BMC Bioinformatics. 2010;11:7.

70. Seemann T. Prokka: rapid prokaryotic genome annotation. Bioinformatics. 2014;30(14):2068-9.

71. Carattoli A, Zankari E, García-Fernández A, Larsen MV, Lund O, Villa L, Aarestrup FM, Hasman H. In silico detection and typing of plasmids using PlasmidFinder and plasmid multilocus sequence typing. Antimicrob Agents Chemother. 2014;58:3895-903.

72. Zankari E, Hasman H, Cosentino S, Vestergaard M, Rasmussen S, Lund O, Aarestrup FM, Larsen MV. Identification of acquired antimicrobial resistance genes. J Antimicrob Chemother. 2012;67:2640-4.

73. Inouye M, Dashnow H, Raven LA, Schultz MB, Pope BJ, Tomita T, Zobel J, Holt KE. SRST2: rapid genomic surveillance for public health and hospital microbiology labs. Genome Med. 2014;6:90.

74. Chen L, Yang J, Yu J, Yao Z, Sun L, Shen Y, Jin Q. VFDB: a reference database for bacterial virulence factors. Nucleic Acids Res. 2005; 33(Databaseissue):D325-8.

\section{Ready to submit your research? Choose BMC and benefit from:}

- fast, convenient online submission

- thorough peer review by experienced researchers in your field

- rapid publication on acceptance

- support for research data, including large and complex data types

- gold Open Access which fosters wider collaboration and increased citations

- maximum visibility for your research: over $100 \mathrm{M}$ website views per year

At BMC, research is always in progress.

Learn more biomedcentral.com/submissions 